\title{
Neonatal Outcome Among Adolescent and Adult Pregnancy in a Tertiary Care Center of Nepal
}

\author{
Adhikari $J^{1}$, Kharel $\mathrm{S}^{2}$, Bahl $\mathrm{L}^{3}$, Poudel $\mathrm{D}^{4}, \mathrm{KC} \mathrm{R}^{5}$
}

\begin{abstract}
BACKGROUND: Teenage pregnancy is a common public health problem worldwide which is detrimental to the health of mother and child and has long been considered a high-risk situation. The risk of low birth weight (LBW) and preterm delivery is particularly high among teenagers. Methods: A comparative study was conducted in Nepalgunj Medical College Teaching Hospital, Kohalpur during the period of July 2015 to June 2016 . The study was carried out to compare the immediate neonatal outcome and morbidity pattern in neonates of 50 adolescent and 50 adult mothers. Results: In the present study, $84 \%$ belonged to adolescent mother group (17-19 years) whereas $50 \%$ belonged to adult mother group (20-23 years). Illiteracy was seen more in adolescent mothers (62\%) and most were from rural areas (68\%). The common immediate neonatal outcome found in adolescent and adult mothers were preterm delivery (96\% vs. 52\%; p value 0.001$)$, low birth weight (LBW) (70\% vs. $38 \%$; p value 0.001$)$. The common neonatal morbidities seen significantly high in neonates of adolescent mothers, viz: Neonatal sepsis (NNS)(54\% vs. $20 \%$ p value $<0.02)$, apnea (30\% vs. $14 \%$ P value $<0.02)$, neonatal jaundice(NNJ)(44\% vs. $30 \%$ p value $<0.01)$ while the other morbidities found were birth asphyxia $(20 \%$ vs. $14 \%$; p value <0.1), Respiratory distress syndrome (RDS) ( $36 \%$ vs. $24 \%$ p value $<0.1$ ), anemia ( $16 \%$ vs. $8 \%$; $p$ value $<0.1$ ), seizure ( $10 \%$ vs. $8 \% ; p$ value $<0.1)$, meconium aspiration syndrome (MAS) $(6 \%$ vs. $18 \%$; $p$ value<0.1) and intrauterine growth retardation(IUGR)( $22 \%$ vs. $20 \%$; p value $<0.5)$. Similarly mortality was found to be more in neonates of adolescent mothers $(14 \%$ vs. $8 \%$; p value $<0.1$ ). Conclusion: Adolescent pregnant mothers are at risk of having poor neonatal outcome and morbidities like NNS, NNJ, RDS, apnea, IUGR, birth asphyxia, anemia and seizure.
\end{abstract}

Key words: Adolescent and adult pregnancy, neonate, Nepalgunj Medical College

\section{INTRODUCTION}

Adolescence is a period of development from 10 years to 19 years of age $\mathrm{e}^{1,2}$. Adolescence proceeds across three distinct period of life: early, middle and late ${ }^{3}$. In this period of life, the body structures undergo many rapid changes including biologic, physiologic and social. The biologic changes in the body are: appearance of the secondary sexual characteristics, development of the body structures to an adult size and complete development of reproductive capacity ${ }^{3}$.

Anxiety and interest in sex and sexual anatomy increases during early puberty. They are less likely to be insecure about health, sexual health and also less likely to receive preventive care, than all other age groups ${ }^{1}$. It is estimated that globally about 13 million infants are born to adolescents out of which more than $90 \%$ occur in developing countries, especially in sub-
1. Dr. Jyoti Adhikari
2. Dr. Shristi Kharel
3. Dr. Lalita Bahl
4. Dr. Deepal Poudel
5. Dr. Rajesh K.C.

Address for correspondence:

Dr. Jyoti Adhikari

Department of Pediatrics

Nepalgunj Medical College

Teaching Hospital Kohalpur, Banke, Nepal

Email: adhikarijyoti@yahoo.com
Saharan Africa ${ }^{4}$. South Asian countries (India, Pakistan, Sri Lanka, Nepal, Maldives, Bhutan and Bangladesh) have high proportions of teenage pregnancies, since early marriage is common and there is a social expectation to have a child soon after marriage $e^{5,6}$.

According to United Nations Population Fund (UNFPA), out of 500 million adolescent girls in the developing world, more than 3 million of them aged 10 to 19 years live in Nepal. ${ }^{7}$ Adolescents comprise $34.6 \%$ of the Nepalese population. The median age at first marriage for a woman in Nepal is 16.6 years, suggesting that the majority of newly married couples are teenagers and in overall, $17 \%$ of women between $15-19$ years starts childbearing ${ }^{8}$.

Keeping in mind the large percentage of neonatal complications in adolescent pregnancies, it has been found that adolescent pregnancies have a greater toll in the adverse neonatal outcome as compared to the few in adult pregnancies. The teen marriage practices exist more in the mid western part of Nepal. Such study has not been done earlier from this part of country, therefore this study was undertaken to compare the neonatal outcome in adolescent and adult mothers.

\section{MATERIAL AND METHODS}

A hospital based comparative study was carried out among 50 adolescent mothers aged $10-19$ years and 50 adult mothers aged 20-30 years in the department of pediatrics, Nepalgunj 
Medical College Teaching Hospital (NGMCTH), Kohalpur, Banke over a period of one year from July 2015 to June 2016. The study was undertaken in newborns admitted in NICU, and in postnatal ward. Mothers who came for the delivery in NGMCTH, Kohalpur and those who gave consent for the study were included whereas those who delivered outside NGMCTH and who did not give consent were excluded from the study. The details of the maternal risk factors and delivery of neonates were recorded in the pre-designed proforma. The statistical software SPSS 20.0 was used for the analysis of the data and Microsoft Excel have been used to generate table.

\section{RESULTS}

\begin{tabular}{|c|c|c|c|}
\hline \multicolumn{2}{|c|}{ Adolescent mothers } & \multicolumn{2}{c|}{ Adult mothers } \\
\hline Age (yrs) & $\begin{array}{c}\text { Frequency } \\
\text { No. (\%) }\end{array}$ & Age (yrs) & $\begin{array}{c}\text { Frequency } \\
\text { No. (\%) }\end{array}$ \\
\hline $10-13$ & $0 \%$ & $20-23$ & $25(50 \%)$ \\
\hline $14-16$ & $8(16 \%)$ & $24-26$ & $16(32 \%)$ \\
\hline $17-19$ & $42(84 \%)$ & $27-30$ & $9(18 \%)$ \\
\hline
\end{tabular}

Table I: Frequency distribution of pregnant mothers by different age group $(n=100)$

Among adolescent populations, maximum number 42 (84\%) were from age group of 17-19 years whereas in adult pregnant women, 25 (50\%) belonged to $20-23$ years group.

\begin{tabular}{|l|c|c|}
\hline Variables & Adolescent mothers & Adult mothers \\
\hline \multicolumn{3}{|c|}{ Place of residence } \\
\hline Rural & $34(68 \%)$ & $32(64 \%)$ \\
\hline Urban & $16(32 \%)$ & $18(36 \%)$ \\
\hline \multicolumn{3}{|c|}{ Education } \\
\hline Illiterate & $31(62 \%)$ & $29(58 \%)$ \\
\hline Literate & $19(38 \%)$ & $21(42 \%)$ \\
\hline
\end{tabular}

Table II: Showing place of residence and education among both groups
In the study majority of adolescent mothers were from rural areas $34(68 \%)$ and illiterate $31(62 \%)$ as compared to the adult mothers.

$96 \%$ of the pregnant adolescent mothers as compared to $52 \%$ of adult pregnant mothers delivered prematurely, full term delivery was seen less in adolescent mothers (4\% vs. $40 \%$ ) while $8 \%$ of post dated delivery was seen only in adult pregnant group which is statistically significant ( $P$ value $<0.001$ )

Extremely low birth weight (ELBW), very low birth weight (VLBW) and low birth weight (LBW) newborns were significantly higher in adolescent mothers $6(12 \%), 9(18 \%)$, and $20(40 \%)$ as compared to adult mothers $1(2 \%), 8(16 \%)$ and 10 (20\%) respectively. On the other hand, adult mothers delivered higher number of normal birth weight newborns 31 (62\%) than adolescent mothers 15 (30\%) (P value 0.05)

In this study the common neonatal morbidities seen significantly high in neonates of adolescent mothers were neonatal sepsis (NNS) (54\% vs. $20 \%$ p value $<0.02$ ), apnea ( $30 \%$ vs. $14 \% \mathrm{P}$ value $<0.02)$, neonatal jaundice(NNJ)( $44 \%$ vs. $30 \% \mathrm{p}$ value $<0.01$ ) while the other morbidities found were birth asphyxia ( $20 \%$ vs. $14 \%$ p value $<0.1)$, respiratory distress syndrome (RDS) ( $36 \%$ vs. $24 \%$ p value $<0.1)$, anemia ( $16 \%$ vs. $8 \%$, seizure $(10 \%$ vs. $8 \% p$ value $<0.1)$ and intrauterine growth retardation (IUGR) $(22 \%$ vs. $20 \%$ p value $<0.5)$

The mortality was more in the neonates of adolescent mother than of adult mothers ( $14 \%$ vs. $8 \%$, p value 0.1 ).

\section{DISCUSSION}

Adolescent pregnancy is hazardous to both the mothers and to the newborns. As adolescence is a period of development in which many changes occur in the body and once the girl at this age gets pregnant when she is still growing, would be a great risk for a mother herself and for the fetus ${ }^{1,2}$.

\begin{tabular}{|c|c|c|c|c|c|c|}
\hline \multirow{2}{*}{$\begin{array}{c}\text { Birth weight } \\
\text { (gm) }\end{array}$} & \multicolumn{2}{|c|}{ Adolescent mothers } & \multicolumn{3}{|c|}{ Adult mothers } & $\begin{array}{c}\text { P } \\
\text { value }\end{array}$ \\
\cline { 2 - 6 } & $\begin{array}{c}14-16 \text { yrs } \\
(\%)\end{array}$ & $\begin{array}{c}17-19 \text { yrs } \\
(\%)\end{array}$ & $\begin{array}{c}20-23 \text { yrs } \\
(\%)\end{array}$ & $\begin{array}{c}24-26 \text { yrs } \\
(\%)\end{array}$ & $\begin{array}{c}27-30 \\
\text { yrs }(\%)\end{array}$ & \\
\hline$<1000$ & $3(6 \%)$ & $3(6 \%)$ & $1(2 \%)$ & $0(0 \%)$ & $0(0 \%)$ & \multirow{2}{*}{0.05} \\
\hline$<1500$ & $1(2 \%)$ & $8(16 \%)$ & $5(10 \%)$ & $2(4 \%)$ & $1(2 \%)$ \\
\cline { 1 - 6 } & $4(8 \%)$ & $16(32 \%)$ & $6(12 \%)$ & $3(6 \%)$ & $1(2 \%)$ & \\
\hline$>2500$ & $0(0 \%)$ & $15(30 \%)$ & $13(26 \%)$ & $12(24 \%)$ & $6(12 \%)$ & \\
\hline
\end{tabular}

Table III: Showing the gestational age of newborns among both groups 


\begin{tabular}{|c|c|c|c|c|c|c|}
\hline \multirow{2}{*}{$\begin{array}{c}\text { Birth } \\
\text { weight } \\
\text { (gm) }\end{array}$} & \multicolumn{2}{|c|}{$\begin{array}{c}\text { Adolescent } \\
\text { mothers }\end{array}$} & \multicolumn{3}{|c|}{ Adult mothers } & $\begin{array}{c}\text { P } \\
\text { value }\end{array}$ \\
\cline { 2 - 6 } & $\begin{array}{c}14-16 \\
\text { yrs (\%) }\end{array}$ & $\begin{array}{c}17-19 \\
\text { yrs (\%) }\end{array}$ & $\begin{array}{c}20-23 \\
\text { yrs (\%) }\end{array}$ & $\begin{array}{c}24-26 \\
\text { yrs (\%) }\end{array}$ & $\begin{array}{c}27-30 \\
\text { yrs (\%) }\end{array}$ & \\
\hline$<1000$ & $3(6 \%)$ & $3(6 \%)$ & $1(2 \%)$ & $0(0 \%)$ & $0(0 \%)$ & \\
\hline$<1500$ & $1(2 \%)$ & $8(16 \%)$ & $5(10 \%)$ & $2(4 \%)$ & $1(2 \%)$ & \multirow{2}{*}{0.05} \\
\hline$<2500$ & $4(8 \%)$ & $16(32 \%)$ & $6(12 \%)$ & $3(6 \%)$ & $1(2 \%)$ & \\
\hline$>2500$ & $0(0 \%)$ & $15(30 \%)$ & $13(26 \%)$ & $12(24 \%)$ & $6(12 \%)$ & \\
\hline
\end{tabular}

Table IV: Showing birth weights of the neonates of adolescent and adult mothers.

\begin{tabular}{|l|l|l|l|l|l|l|l|c|}
\hline Morbidity & $\begin{array}{r}\text { 14-16 } \\
\text { years } \\
\mathbf{n}(\%)\end{array}$ & $\begin{array}{r}\text { 17-19 } \\
\text { years } \\
\mathbf{n}(\%)\end{array}$ & $\begin{array}{c}\text { Adolescent } \\
\text { mothers } \\
\text { Total (\%) }\end{array}$ & $\begin{array}{r}\mathbf{2 0 - 2 3} \\
\text { years } \\
\mathbf{n}(\%)\end{array}$ & $\begin{array}{c}\mathbf{2 4 - 2 6} \\
\text { years } \\
\mathbf{n}(\%)\end{array}$ & $\begin{array}{c}\mathbf{2 7 - 3 0} \\
\text { year, } \\
\text { n (\%) }\end{array}$ & $\begin{array}{c}\text { Adult } \\
\text { mothers } \\
\text { Total (\%) }\end{array}$ & P value \\
\hline NNS & $6(12 \%)$ & $21(42 \%)$ & $27(54 \%)$ & $7(14 \%)$ & $1(2 \%)$ & $2(4 \%)$ & $10(20 \%)$ & 0.001 \\
\hline NNJ & $4(8 \%)$ & $18(36 \%)$ & $22(44 \%)$ & $10(20 \%)$ & $1(2 \%)$ & $4(8 \%)$ & $15(30 \%)$ & 0.01 \\
\hline RDS & $3(6 \%)$ & $15(30 \%)$ & $18(36 \%)$ & $8(16 \%)$ & $2(4 \%)$ & $2(4 \%)$ & $12(24 \%)$ & 0.10 \\
\hline Apnea & $4(8 \%)$ & $11(22 \%)$ & $15(30 \%)$ & $2(4 \%)$ & $3(6 \%)$ & $2(4 \%)$ & $7(14 \%)$ & 0.02 \\
\hline IUGR & $3(6 \%)$ & $8(16 \%)$ & $11(22 \%)$ & $6(12 \%)$ & $3(6 \%)$ & $1(2 \%)$ & $10(20 \%)$ & 0.50 \\
\hline $\begin{array}{l}\text { birth } \\
\text { asphyxia }\end{array}$ & $2(4 \%)$ & $8(16 \%)$ & $10(20 \%)$ & $4(8 \%)$ & $2(4 \%)$ & $1(2 \%)$ & $7(14 \%)$ & 0.10 \\
\hline Anemia & $2(4 \%)$ & $6(12 \%)$ & $8(16 \%)$ & $1(2 \%)$ & $1(2 \%)$ & $2(4 \%)$ & $4(8 \%)$ & 0.10 \\
\hline MAS & 0 & $3(6 \%)$ & $3(6 \%)$ & $5(10 \%)$ & $3(6 \%)$ & $1(2 \%)$ & $9(18 \%)$ & 0.10 \\
\hline seizure & $1(2 \%)$ & $4(8 \%)$ & $5(10 \%)$ & $2(8 \%)$ & $2(8 \%)$ & 0 & $4(8 \%)$ & 0.10 \\
\hline
\end{tabular}

Table V: Morbidity pattern in neonates

In this study, most of the adolescents (84\%) were of late adolescent i.e. 17-19 years and none from early adolescent age group i.e.10-13 years. Most of the adult mothers (50\%) belonged to $20-23$ years age group, $32 \%$ was found to be from 24-26 years age group and $18 \%$ belonged to $27-30$ year age group. These findings are similar to the another study from India where maximum number of teenage mothers were of 17 to 19 years $(38.2 \%)$, less in middle age $(27.9 \%)$ and none were from early adolescence age group ${ }^{9}$.

The majority of adolescent mothers and the adult mothers in this study belonged to rural areas than urban areas $(68 \%$ vs.64\%) because, the place where this study was done is a tertiary care hospital situated in mid-western part of Nepal, which includes mainly rural areas with poor health facilities. Also illiteracy was more in adolescent mothers than adult mothers. ( $62 \%$ vs. $58 \%$ ) which is similar with the another study done in Nepal. ${ }^{10}$ An illiterate mother would not be able to read and their lack of information would make them vulnerable to get pregnant during adolescent period. The female from the rural areas get fewer opportunities for education; and get early married under the influence of social taboos. This shows that in Nepal illiteracy is a common risk factor for women to become pregnant in young age of her life.

In the present study preterm deliveries were found more in the adolescent mothers than the adult mothers (96\% vs. $52 \%$, $p$ value $<0.001$ ), while full term delivery was seen more in the adult mothers then adolescent mothers ( $40 \%$ vs. $4 \%$ ). This finding is similar with various studies ${ }^{11,12,13,14}$. The reason for significant high number of preterm delivery seen in adolescent pregnant women is probably because of the biological immaturity ${ }^{15}$. Immaturity of the uterine or cervical blood supply may predispose teenage mothers to subclinical infection, an increase in prostaglandin production, has been found leading to consequent increase in the incidence of preterm delivery. ${ }^{12,16}$

The present study found that the adolescent mothers delivered more number of LBW infants as compared to adult mothers (70\% vs. $38 \%$ ) The more number of ELBW infants were born to 
adolescent mothers than the adult mothers ( $12 \%$ vs. $2 \%, p$ value $<0.05)$. This result is similar with many other studies $^{14,17,18,19}$.

In this study the common neonatal morbidities seen significantly high in neonates of adolescent mothers were neonatal sepsis, apnea, neonatal jaundice while the other morbidities found were birth asphyxia, respiratory distress syndrome, anemia, seizure and intrauterine growth retardation which were found more in infants of teenage mothers. These finding are in consistent with various other studies $^{13,18,19,20,21,22}$. The more number of NNS in newborn of adolescent mothers in our study could be explained because of immature immune system of newborn in addition to poor hygiene of mothers increased the chance of ascending infection.

Gestational age is the most important determinant of respiratory control, with the frequency of apnea being inversely related to gestational age. In present study apnea and RDS is found more in the preterm and LBW infants because the lungs of the preterm neonates are not fully developed due to surfactant deficiency ${ }^{21,22}$.

In the study mortality of neonates was more in neonates of adolescent mothers than of adult mothers ( $14 \%$ vs. $8 \%$ ).The result of present study is similar with other study from $\mathrm{Nepal}^{23}$.

\section{CONCLUSION}

Adolescent pregnant mothers are at risk of having poor neonatal outcome and morbidities like NNS, NNJ, RDS, apnea, IUGR, birth asphyxia, anemia and seizure. Illiteracy, lack of knowledge about reproductive and sexual health is one of the common factors that make adolescents vulnerable to risky behaviors and subsequently have poor neonatal outcome. So for better outcome of neonates, it is important to reduce the incidence of adolescence pregnancy which is possible when teenagers are given proper education, information and counseling about sexual health and reproductive health.

\section{ACKNOWLEDGEMENTS}

My sincere thanks to Lord Buddha Educational Academy, NGMCTH, Kohalpur administration, Principal's office and pediatric department for their valuable contribution.

\section{REFERENCES}

1. World Health organization. Adolescent pregnancy: issues in adolescent health and development. Geneva: World Health Organization; 2004. p.5.

2. Godbole T.G., Bhatia V. Adolescent health and development In: Paul V.K, Bagga A. Ghai Essential Pediatrics. $8^{\text {th }}$ ed. India: CBS publication; 2009. p. 63-9.

3. HH Cynthis, BR Gale. Adolescent Medicine In: Kleighman, Stanton, St.Geme, Schor Nelson's Textbook of Pediatrics. $20^{\text {th }}$ ed. Philadelphia: Elsevier; 2016. p. 926-31.

4. Mclntosh N, Helma P, Smith R, editors. Forfar and Arneil's textbook of Pediatrics, $6^{\text {th }}$ edition. Edinburg, Churchill Livingstone; 2003. p. 130-1.

5. Stone N, Ingham R, Simkhada P. Knowledge of sexual health issues among unmarried young people in Nepal. Asia-Pacific Population J 2003; 18: p. 33-54.

6. Mathur S, Metha M, Malhotra A. Youth reproductive health in Nepal: is participation the answer? Engender Health, ICRW 2004;1-77

7. United Nations Population Fund. Teenage Pregnancies: Growing challenge. Nov 2013;08:07(10).

8. Nepal Demographic and Health Survey (NDHS). 2016. p. 13.

9. Kumar A, Singh T, Basu S, Pandey S, Bhargava V. Outcome of teenage pregnancy. The Indian Journal of Pediatrics. 2007;74(10):927-31.

10. Gortzak-Uzan L, Hallak M, Press F, Katz M, Shoham-Vardi I. Teenage pregnancy: risk factors for adverse perinatal outcome. Journal of Maternal-Fetal Medicine. 2001;10(6):393-7.

11. Mukhopadhyay P, Chaudhuri RN, Paul B. Hospital-based perinatal outcomes and complications in teenage pregnancy in India. Journal of Health, Population and Nutrition. 2010: p. 494-500.

12. Kumar A, Singh T, Basu S, Pandey S, Bhargava V. Outcome of teenage pregnancy. The Indian Journal of Pediatrics. 2007;74(10):927-31.

13. Edessy M, Gaber M, Rahman A. Teenage pregnancy and fetal outcome. American Journal of Research Communication, 2014; 2(10):169-75.

14. Suciu LM, Pasc AL, Cucerea M, Bell EF. Teenage Pregnancies: Risk Factors and Associated Neonatal Outcomes in an EasternEuropean Academic Perinatal Care Center. American journal of perinatology. 2016;33(04):409-14.

15. Nili F, Rahmati MR, Sharifi SM. Maternal and neonatal outcome in teenage pregnancy in Tehran Valiasr Hospital. Acta Medica Iranica. 2002; 40(1):55-9.

16. Kushwaha KP, Rai AK, Rathi AK, Singh YD, Sirohi R. Pregnancies in adolescents: fetal, neonatal and maternal outcome. Indian pediatrics. 1993;30(4):501-5.

17. Salama B, El-Taher S. Pregnancy related complications and neonatal outcomes among primigravida teenage mothers. The Egyptian Journal of Community Medicine 2012; 30(2): 16-24.

18. Rudra S, Bal H, Singh S. A retrospective study of teenage pregnancy in a tertiary care hospital. Int J Reprod Contracept Obstet Gynecol. 2013;2(3):383-7.

19. Dutta I, Joshi P. Maternal and perinatal outcome in teenage vs. Vicenarian primigravidae-a clinical study. J Clin Diagn Res. 2013;7(12):2881-4.

20. Puchner AM.Boutsikou T.Adolescent Pregnancy and Perinatal outcome. Pediatr Endocrinol Rev 2006; 3 Suppl 1:170-1.

21. Dutta D.C. Disease of fetus and newborn.Text book of obstetrics. $8^{\text {th }}$ Edition. India: Central Publications, 2015. p. 547-8

22. Singh M. Repiratory disorder. Care of the Newborn, $8^{\text {th }}$ edition. India: Sagar publication, 2014. p. 349-51.

23. Lama L, Shrestha S, Sharma A, Upadhyay S, Pathak MR. Immediate neonatal outcome of adolescent pregnant mother at Nepal Medical College Teaching Hospital. Nepal Med Coll J: NMCJ. 2012 Jun;15(1):117-21. 